\title{
Multiple Groundwater Parameters and Environmental Changes using Geospatial Techniques in the Permian Basin, Texas
}

\author{
Robert Nelson \\ Department of Geosciences, University of Texas Permian Basin, Odessa, TX 79762, USA \\ Staff Geoscientist, Larson and Associates, Midland, TX 79701, USA \\ Email: nelson_r8014@utpb.edu \\ Joonghyeok Heo* \\ Department of Geosciences, University of Texas Permian Basin, Odessa, TX 79762, USA \\ Email: joonghyeok.heo@gmail.com \\ * Corresponding Author
}

\begin{abstract}
This study evaluates spatial analyses of groundwater quality and environmental changes to obtain information on the groundwater contamination in the Permian Basin, Texas. Coupled with the U.S. government's open data, these analyses can identify regions where environmental change could have potentially effected groundwater quality. A total of thirty-six wells were selected within the six counties: Andrews, Martin, Ector, Midland, Crane, and Upton. Spatial distribution maps were created for six different parameters: $\mathrm{pH}$, total dissolved solids (TDS), chloride, fluoride, nitrate, and arsenic. Total groundwater quality maps incorporate all the contaminants and denote regions of poor, medium, and optimum conditions. To identify spatial changes in groundwater quality, maps were separated into two different time intervals, 19922005 and 2006-2019. We found that groundwater contamination resulted primarily from the mobilization of the contaminant from natural sources or anthropogenic activities such as chemical fertilizers. Overall, groundwater quality decreased during the study period from 1992 to 2019 as population and urban growth began to develop in the Permian Basin. This study contributes on understanding of the response of groundwater quality associated with environmental change in the Permian Basin. Therefore, this research provides important information for groundwater managements in developing plans for the use of water resource in the future for Texas.
\end{abstract}




\section{Keywords}

Groundwater quality; Environmental change; Permian Basin; Texas

\section{Introduction}

Groundwater accounts for approximately 32 percent of all water supplied by municipal water treatment facilities. As population continues to rise, there will be a heavier reliance on this diminishing natural resource. The Safe Water Drinking Act (SWDA), established by Congress in 1974, developed groundwater quality regulations at municipal water treatment facilities, and supervises more than 150,000 of these facilities to ensure groundwater quality standards are meet [1]. Citizens obtaining their water from privately owned water wells in rural areas not serviced by local water treatment facilities should take preventative steps such as testing and decontamination prior to consumption, as these wells are not regulated by the Environmental Protection Agency (EPA).

Once the EPA has determined that a contaminant poses a risk to water quality, they will develop a maximum contaminant level goal (MCLG). The maximum contaminant level goal is achieved when the most vulnerable individuals, such as infants, children, and the elderly, would not experience adverse health effects from exposure of the contaminant [2-3]. After the EPA has developed a MCLG for a contaminant, then the agency sets a maximum contaminant level (MCL). The EPA enforces MCL's within the municipal water treatment facilities to maintain water quality but in order to enforce the MCL, they must be both economically and technologically viable $[1,4]$. The three chemically derived contaminants that are not controlled by the EPA in this study are chloride, $\mathrm{pH}$, and total dissolved solids (TDS). The remaining three contaminants, arsenic, fluoride, and nitrate, have specific MCLG/MCL values determined by the EPA.

Numerous studies have been conducted to identify the effect of oil and gas production on groundwater quality and land-use changes [5-8]. Unconventional oil and gas production provide a variation of groundwater quality over time in the Permian Basin, West Texas [5, 6]. The landuse changes in West and Central Texas during the shale boom of 2008-2012 are a direct result from the utilization for unconventional reservoirs and the development of energy resources and 
other human contributing activities [7, 8]. However, no studies have combined both parameters to identify how energy development and environmental change relate to groundwater quality.

Some studies have been undertaken to estimate the groundwater quality according to oil and gas development in the US [9-12]. Various States, like California, Wisconsin, Ohio, Minnesota, Pennsylvania, Arkansas, and Colorado have had studies discussing the changes to groundwater quality since hydraulic fracturing had been introduced to each area. Long [9] studied some challenges for groundwater quality from the oil and gas industries in the States of Wisconsin and Minnesota. Even though it is challenging to determine the impact of oil and gas activities to groundwater aquifers, there are evidences that important parameters like $\mathrm{pH}$ and salinity are affected $[10,11]$. Thus, major ions of chloride $(\mathrm{Cl})$ should be monitored to ensure groundwater quality. EPA also mention that levels of total dissolved solids (TDS) can be affected by hydraulic fracturing practices [12].

Recent advances in oil recovery from unconventional reservoirs have drastically increased oil production operations in the Permian Basin [13-15]. The area in which this research is conducted is generally utilized for ranching, agriculture, and oil and gas production [14]. Due to the importance of groundwater in the production of these valuable commodities, maintaining stable groundwater is a necessity. As a result, a sharp increase in population and urban growth in west Texas has altered the landscape, potentially changing groundwater quality [15]. Therefore, further research on the Permian Basin, West Texas must be conducted in order to obtain a better understanding of the effects of groundwater quality over time.

The purposes of this research are to 1) describe an overview of current groundwater quality in the Permian Basin, 2) determine spatial distribution of groundwater quality parameters such as $\mathrm{pH}$, TDS, chloride, fluoride, nitrate, and arsenic concentrations, and 3) provide total groundwater quality and environmental change maps from 1992 to 2019 in the study area. This research contributes to understanding of the responses of groundwater resources in the Permian Basin, Texas. Thus, this research can provide important information for groundwater resources manager in making decision and developing plans for use of the groundwater resources in the future. 


\section{Study Area}

The study area is located in Western Texas which has a total area of $538.98 \mathrm{~km}^{2}$. It extends across six counties of Texas; Andrews, Martin, Ector, Midland, Crane, and Upton (Fig 1). The land cover of the study area consists mostly of developed, barren, bush, grass, and crop. The alluvial environment in which the sediments were deposited consisted of interbedded sand, silt, clay, and gravel filling prehistoric river valleys [16]. Deposition of this aquifer began during the late Miocene to the early Pliocene and formed from eastward flowing streams originating from the Rocky Mountains [13].

Groundwater originating from within the study area is captured from four aquifers: Ogallala (major), Pecos Valley (major), Edwards Trinity Plateau (major), and Dockum (minor). The Ogallala aquifer is the largest aquifer in the United States and is a major aquifer of Texas, underlying much of the High Plains region. It consists of sand, gravel, clay, and silt and has a maximum thickness of 800 feet. The Pecos Valley aquifer is one of major aquifer in West Texas. Water bearing sediments include alluvial and windblown deposits in the Pecos River Valley. The Edwards-Trinity Plateau aquifer is a major aquifer extending across much of the southwestern part of the state. Water quality ranges from fresh to slightly saline, and most of the groundwater is used for irrigation, municipal supplies, industrial use, and power generation. The Dockum aquifer is a minor aquifer found in the northwest part of the state. It is a sandstone aquifer and the basal member of the Dockum formation with the upper layers being predominantly siltstone and claystone.

These aquifers are a valuable source of water for ranchers, farmers, and the recovery of oil and gas in the region. The deepest groundwater well is within the Dockum at 1600 feet and the Ogallala contains the shallowest at 70 feet (Fig 2). Recharge of the aquifer occurs primarily through infiltration of precipitation. Due to the high rate of evaporation in this arid region, very little reaches the water table. The recharge rate of this aquifer is lower than the depletion rate with variations from state to state. The study area in West Texas is currently experiencing the highest depletion rate whereas certain areas have seen a drawdown of as much as 100 feet [17]. 


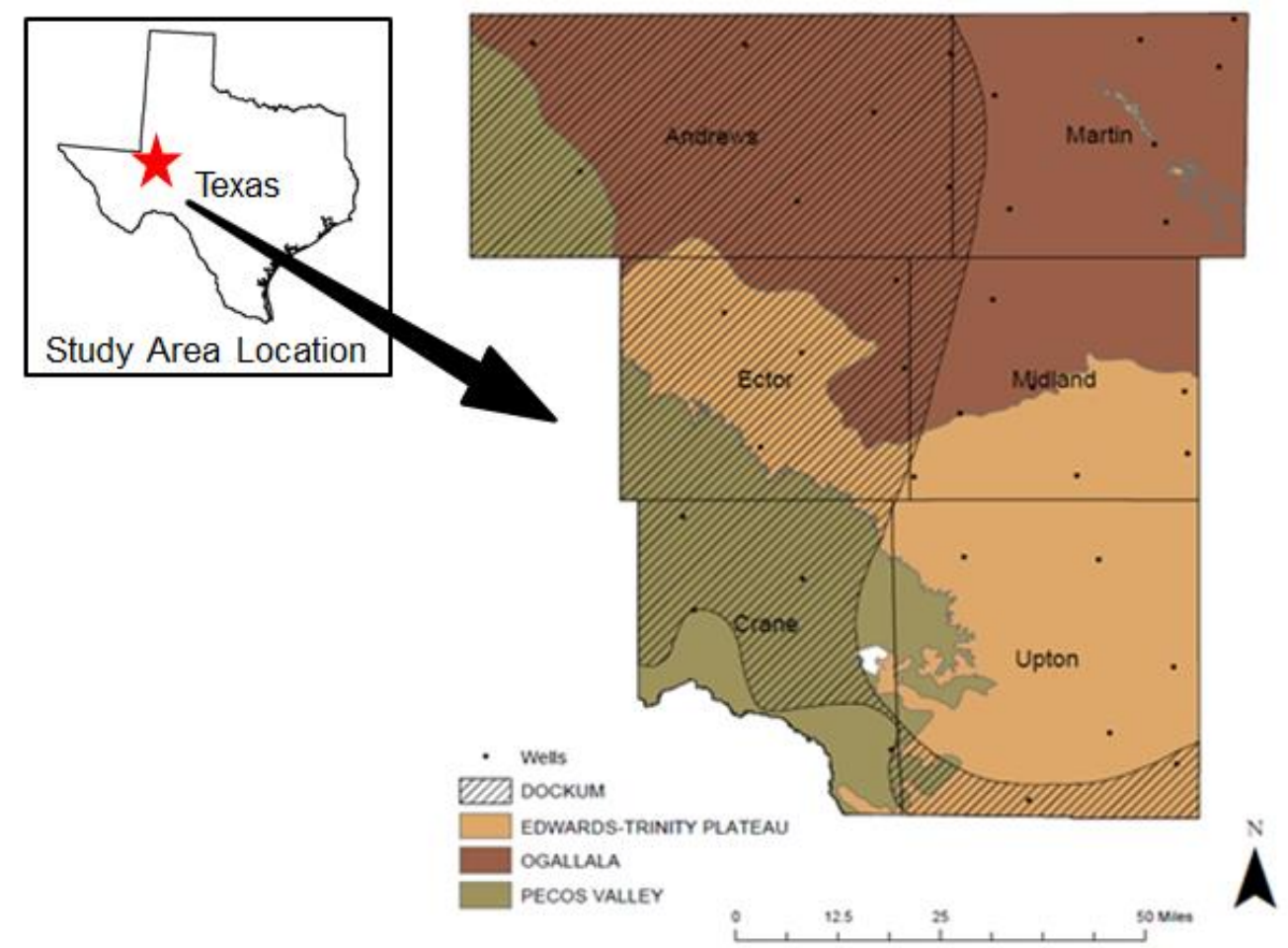

Fig 1. Study area map showing well locations, county and aquifer names.

The study area is categorized as a semi-arid climate, where temperatures can drastically fluctuate throughout the day. The Permian Basin average low temperatures for January are $28^{\circ} \mathrm{F}$ and July high temperatures are $95^{\circ} \mathrm{F}$ [17]. The region receives on average 13-18 inches of rain annually, mostly during the spring (March-May) and early fall months (September-October). During the late summer and early fall months, moist air originating from the tropics begins to rise due to the southwestern monsoon which is the primary producer for rainfall events in west Texas [18]. With this low average rainfall, the evaporation rate is greater than the precipitation rate, resulting in a dry climate with relatively low humidity. 


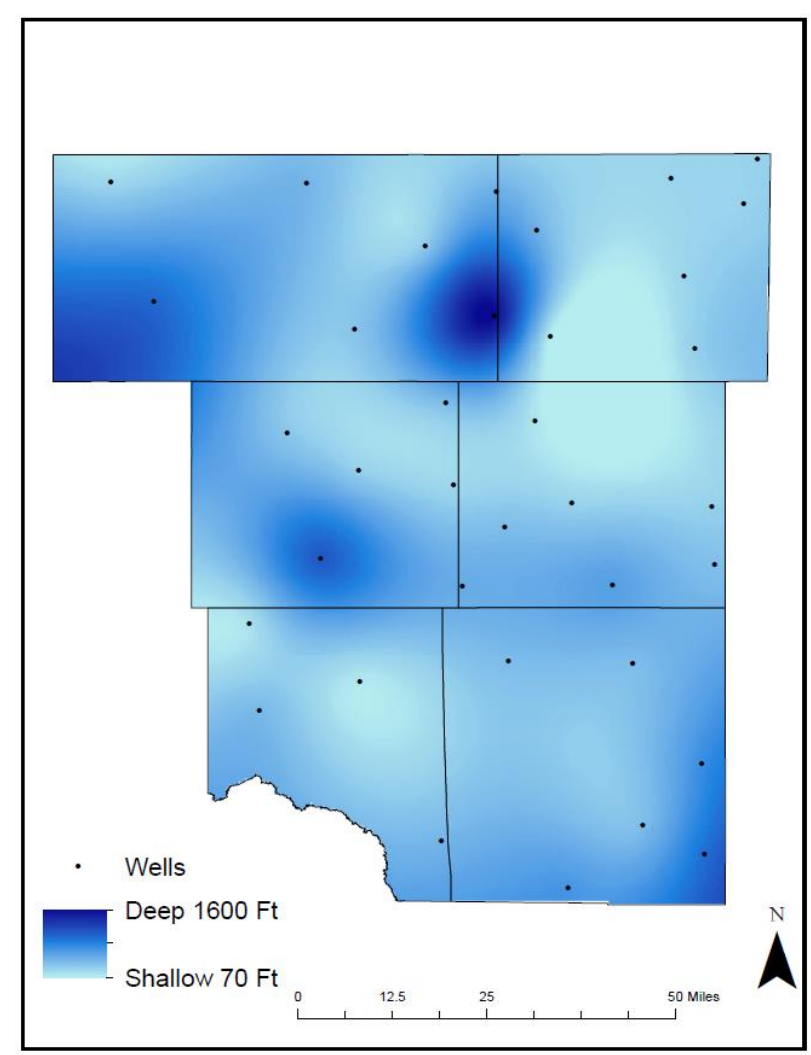

Fig 2. Groundwater well depth in the study area.

\section{Data and Methods}

\subsection{Groundwater quality parameters}

All groundwater data was obtained from the Texas Water Development Board (TWDB) Groundwater Database (GWDB) which is an open database provided by the US government. We collected all historically available data in our study area from TWDB-GWDB and checked the location of their wells. To apply the interpolation analysis with GIS and evaluate the spatial distribution of groundwater qualities, the observed wells must be uniformly distributed throughout the study area [7, 19-21]. For this reason, we finalized the total 36 wells to create an even distribution throughout the study area (Table 1).

For comparing historical changes in groundwater quality, data from 1992-2005 was correlated with data from 2006-2019. The groundwater quality parameters used for this study include $\mathrm{pH}$, and total dissolved solid (TDS), chloride $(\mathrm{Cl})$, fluoride $(\mathrm{F})$, nitrate $\left(\mathrm{NO}_{3}{ }^{-}\right)$, and arsenic (As). The standard quality for water has been specified by EPA and World Health Organization (WHO) (Table 2). The selected groundwater parameters data in the study area were 
required to provide long-term data with a relatively dense hydrological observation network. Each well was mapped within the study area using its provided latitude/longitude coordinate and contaminant concentration level. We followed and developed the methodology from Nas and Berktay [7].

Spline interpolation was implemented to evaluate the spatial distribution of groundwater concentrations in the map. The spline interpolation estimates values using a mathematical function that minimizes overall surface curvature, resulting in a smooth surface for the study area [21]. Once the groundwater maps were created for each different parameter, a map indicating total groundwater quality was produced. According to Nas and Berktay [7], the mosaic to new raster tool was performed by merging the six groundwater maps together while also adding all the variables. The total groundwater map from poor to optimum conditions were classified to denote regions with increasing and decreasing water quality [7, 19]. The map represents a combination of the six groundwater parameters.

Table 1 Summary of well data used in the study area (depth unit: feet. below land surface).

\begin{tabular}{lrrrrl}
\hline County & Well ID & Latitude & Longitude & Depth & Aquifer \\
\hline Andrew & 2750103 & 32.24111 & -102.871 & 490 & Pecos \\
& 2753402 & 32.18833 & -102.486 & 160 & Ogallala \\
& 2755103 & 32.21306 & -102.219 & 1600 & Dockum \\
& 2746101 & 32.3475 & -102.352 & 150 & Ogallala \\
& 2739405 & 32.45139 & -102.215 & 215 & Ogallala \\
& 2736208 & 32.46889 & -102.579 & 200 & Ogallala \\
& 2733202 & 32.47056 & -102.954 & 120 & Ogallala \\
& 2756401 & 32.17361 & -102.111 & 70 & Ogallala \\
& 2850704 & 32.15028 & -101.834 & 135 & Ogallala \\
& 2842705 & 32.28889 & -101.855 & 122 & Ogallala \\
& 2739901 & 32.37764 & -102.137 & 214 & Ogallala \\
& 2833303 & 32.47694 & -101.88 & 125 & Ogallala \\
& 2835401 & 32.42833 & -101.74 & 130 & Ogallala \\
& 2827705 & 32.51472 & -101.714 & 133 & Ogallala \\
& 4520202 & 31.74583 & -102.552 & 1417 & Dockum
\end{tabular}




\begin{tabular}{|c|c|c|c|c|c|}
\hline & 4506809 & 31.88722 & -102.297 & 120 & Edwards \\
\hline & 2762509 & 32.04667 & -102.311 & 180 & Edwards \\
\hline & 4505705 & 31.91519 & -102.479 & 140 & Edwards \\
\hline & 4504107 & 31.98806 & -102.616 & 159 & Edwards \\
\hline Midland & 4522604 & 31.69361 & -102.28 & 225 & Edwards \\
\hline & 4417409 & 31.69417 & -101.992 & 255 & Edwards \\
\hline & 4418214 & 31.73389 & -101.796 & 176 & Edwards \\
\hline & 4515505 & 31.8075 & -102.199 & 180 & Edwards \\
\hline & 2763901 & 32.01083 & -102.141 & 90 & Ogallala \\
\hline & 4410211 & 31.84722 & -101.801 & 135 & Edwards \\
\hline & 4516208 & 31.8525 & -102.071 & 131 & Edwards \\
\hline Crane & 4554501 & 31.20236 & -102.32 & 200 & Dockum \\
\hline & 4529704 & 31.50833 & -102.477 & 80 & Pecos \\
\hline & 4535506 & 31.45472 & -102.669 & 190 & Pecos \\
\hline & 4527203 & 31.62107 & -102.689 & 94 & Pecos \\
\hline Upton & 4564204 & 31.11333 & -102.077 & 280 & Edwards \\
\hline & 4450501 & 31.17639 & -101.815 & 375 & Edwards \\
\hline & 4449201 & 31.23278 & -101.934 & 180 & Edwards \\
\hline & 4442210 & 31.35139 & -101.821 & 300 & Edwards \\
\hline & 4425505 & 31.54389 & -101.953 & 183 & Edwards \\
\hline & 4531501 & 31.5488 & -102.192 & 182 & Edwards \\
\hline
\end{tabular}

Table 2. Standards for groundwater quality by EPA and WHO (EPA: US environmental protection agency, WHO: world health organization, MCL: maximum contamination level)

\begin{tabular}{lr}
\hline Contaminant & MCL $(\mathrm{mg} / \mathrm{L})$ \\
\hline $\mathrm{pH}$ & $6.5-8.5$ \\
$\mathrm{TDS}$ & 500 \\
Chloride & 250 \\
Fluoride & 4 \\
Nitrate & 10 \\
Arsenic & 0.01 \\
\hline
\end{tabular}




\subsection{Examining the environmental change}

The land-cover data was obtained from Texas Natural Resources Information System (TNRIS). TNRIS provided the National Land Cover Data (NLCD) 1992 and 2011 in a raster format. The data has spatial resolution at $30 \mathrm{~m}$ for a single pixel measures 30 meters in width and length, which is 900 meters squared. Raster data management was preformed to merge these raster data sets together. For both images to fit inside the study area, an extract by mask process was performed. This process extracts the raster cells of the imagery data and places them within the county boundaries of the study area. Additionally, we applied spatial analyses to refine the data and identify issues including edge effect, resolution change artifacts, and misclassification (Fig 3). A majority filter was selected to smooth spatial anomalies and to provide a smoother and clearer image [21].

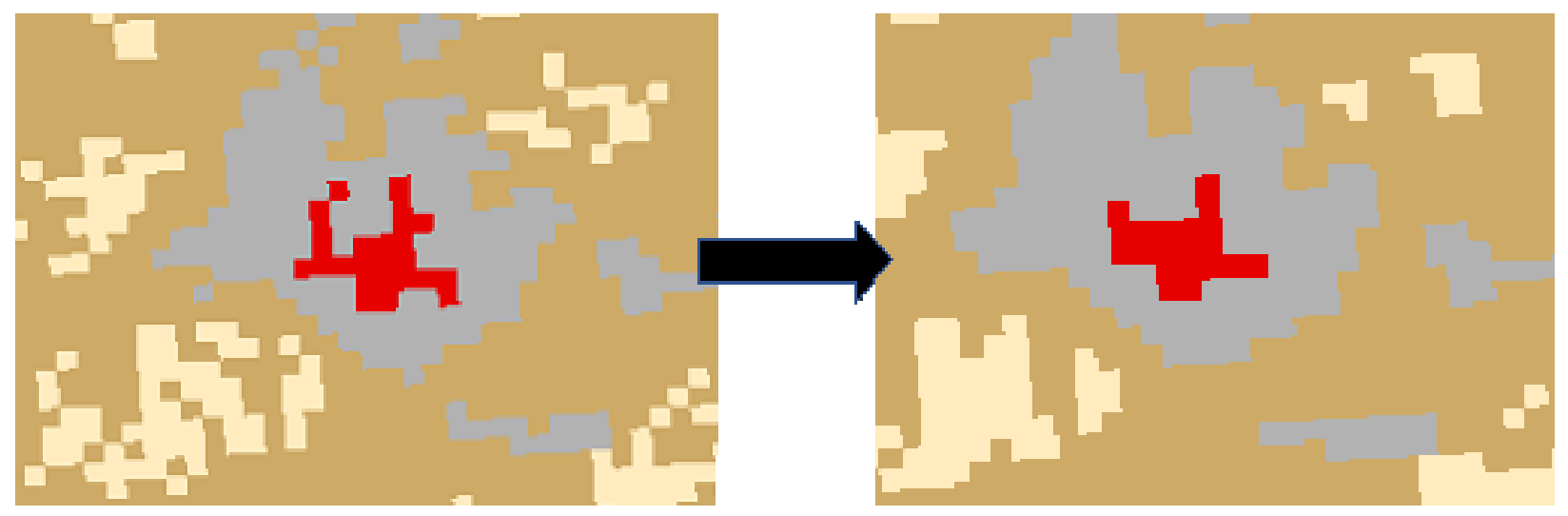

Fig 3. Example of majority filter in the study area.

This research utilized seven different geographic features to describe variations from 1992 to 2011, which include water, developed, barren, forest, bush, grass, and crop (Table 3). In order to correlate between the NLCD 1992 and 2011, a reclassification and grouping of the landcover was required [22, 23]. Developed classification grouped the open space, low, medium, and high intensities, such as urban settlement, transportation and industrial land. Barren classification included the bare land, rock, sand, and clay. Forest category grouped the deciduous, evergreen, and mixed forests. Bush category grouped the shrub and scrub, which is less than six meter high. Crop category included the pasture, hay, cultivated crop. Wetland classification was removed from the 1992 and 2011 maps as their relevancy within this arid region is negligible. 
Table 3 Reclassification and land-cover description for the NLCD 1992 and 2011.

\begin{tabular}{lll}
\hline Reclassification & \multicolumn{2}{c}{ Land-cover description } \\
\cline { 2 - 3 } & NLCD 1992 & NLCD 2011 \\
\hline Water & Open water & Open water \\
Developed & Low, medium, and high intensity & Developed low, medium, and high \\
& residential & intensity \\
Barren & Bare rock/sand/clay & Bare land (rock/sand/clay) \\
Forest & Deciduous and evergreen forest & Deciduous, evergreen, and mixed forest \\
Bush & Shrubland & Shrub/scrub \\
Grass & Grassland/herbaceous & Grassland/herbaceous \\
Crop & Pasture/hay and row crops & Pasture/hay and cultivated crops \\
\hline
\end{tabular}

\section{Results and Discussion}

\section{1. pH}

Municipal water treatment facilities must regulate and balance $\mathrm{pH}$ prior to its distribution, in order to provide optimal water. The concentration of hydrogen $\left(\mathrm{H}^{+}\right)$and hydroxyl $\left(\mathrm{OH}^{-}\right)$ions in a liquid determine the measurement of $\mathrm{pH}$. These measurements decide whether the liquid is an acid, neutral, or alkaline. For this study, it is surmised that soil $\mathrm{pH}$ and groundwater $\mathrm{pH}$ have comparable concentration levels. Within soils, $\mathrm{pH}$ controls the mobility of contaminants such as arsenic and fluoride. As soils become acidic, fluoride mobility increases allowing concentrations to increase [24]. Alternatively, as $\mathrm{pH}$ shifts becoming alkaline, arsenic mobility increases, resulting in elevated concentrations [25]. These fluctuations in $\mathrm{pH}$ control the concentration levels of arsenic and fluoride in groundwater and soils. 

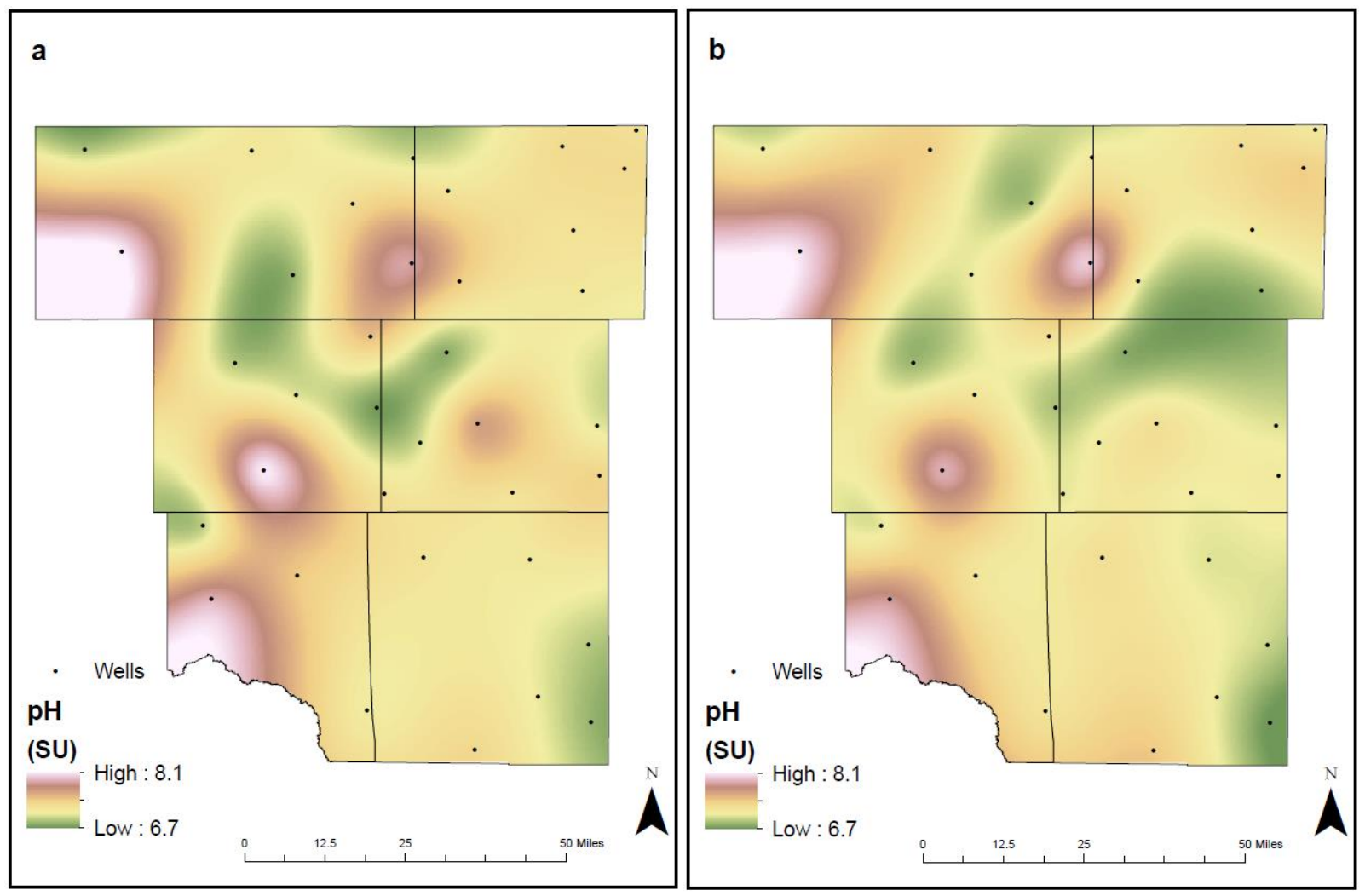

Fig 4. Spatial distribution of $\mathrm{pH}$ in the study area for (a) 1992-2005 and (b) 2006-2019 (SU: standard units).

The $\mathrm{pH}$ in the study area ranges from 6.7 - 8.1 SU (Fig 4), where the deeper wells are more alkaline than the shallower wells. This increase is a result of the aquifers composition, where dissolving limestones and dolomite minerals contribute to the aquifers alkalinity. Corrosive water ( $\mathrm{pH}$ lower than 7 ) has potentially damaging effects on the municipal water treatment facility and the local homeowner. These waters have the potential to corrode pipes and destroy household appliances. The EPA recommends well waters be between 6.5 - 8.5 SU to prevent these damaging effects on infrastructure [26]. Soil $\mathrm{pH}$ is affected by climate, temperature, and parent material [27]. In arid climates, the low precipitation results in soils that are closer to neutral or slightly alkaline due to the weathering and leaching effects of rainfall. The weathering of parent material results in the formation of soil horizons and is the contributing factor to the soils $\mathrm{pH}$. 


\subsection{TDS}

Total dissolved solids (TDS) is a measurement of the dissolved combined content of inorganic salts and small amounts of organic matter that are dissolved in water [3]. These inorganic salts can contaminate the groundwater through anthropogenic or natural activities. Increased agricultural activity can result in higher concentrations of total dissolved solids. The adverse effects of TDS on infrastructure and taste can occur due to increase concentrations $(1,000 \mathrm{mg} / \mathrm{L}$ or greater) in groundwater [26]. To prevent these effects from occurring, while also providing an acceptable taste to the user, it is recommended that the concentration of TDS not exceed 600 $\mathrm{mg} / \mathrm{L}[28]$.

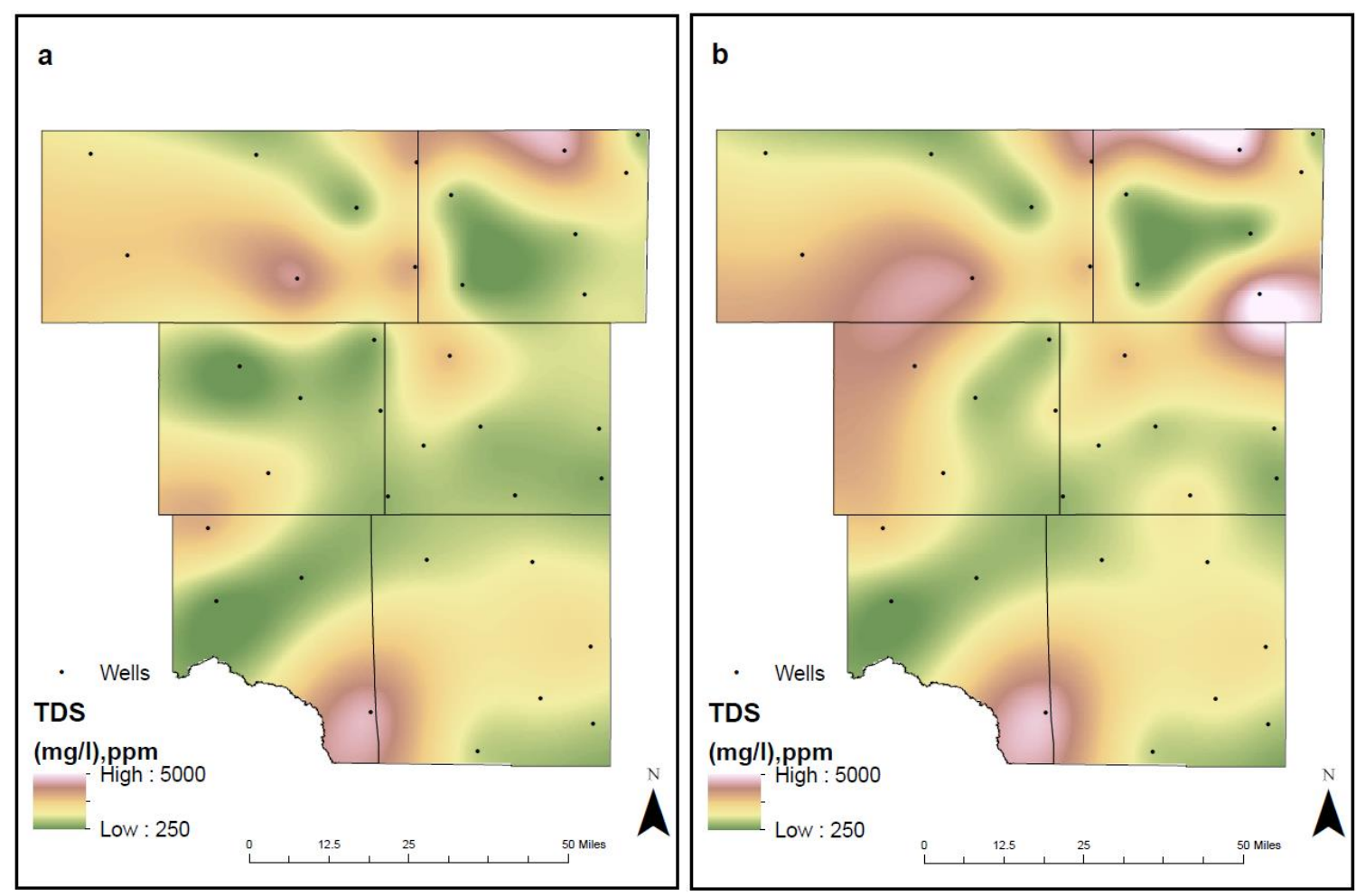

Fig 5. Spatial distribution of TDS in the study area for (a) 1992-2005 and (b) 2006-2019.

As crop land began to develop within Martin County from 1992 to 2011, the concentration of TDS continued to rise. Between 1992-2005 and 2006-2019, concentration levels rose from 1,140mg/L to 5,000 mg/L (Fig 5). Elevated TDS levels can result from plants uptake of water, allowing soil to retain chlorides [28]. When additional precipitation or irrigation is contributed to the soil, these chlorides can leach through the subsurface and reach the underlying 
groundwater. Furthermore, agricultural activities as discussed in section 4.8 (environmental change), environmental changes, chemical fertilizers and concentrated animal feeding operations, contribute to the increase TDS levels observed.

Disposal of oilfield brines resulted in the higher concentrations of TDS levels in northwest Ector County. Concentrations rose from $27.3 \mathrm{mg} / \mathrm{L}$ in $1992-2005$ to 3,322.5 mg/L in 2006-2019 (Fig 5). The developed land-cover change from 1992 to 2011 is noticeable in this area from the development of production pads and salt water disposal sites (Fig 10). TDS levels may also rise from natural weathering of rocks and soils in the subsurface. Regions with limestone and dolomite present can have naturally high levels of TDS due to the presence of calcium.

\subsection{Chloride}

The chloride contamination of groundwater and the water supply have the potential to threaten the environment. The consumer may notice the prevalence of the chloride anion within drinking water at higher concentrations, producing a salty taste. The taste thresholds can range from 200 to $1,000 \mathrm{mg} / \mathrm{L}$ and is determined by its associated cation of either sodium, calcium, or magnesium [3]. Municipal water treatment facilities require sodium chloride concentrations to remain below $250 \mathrm{mg} / \mathrm{L}$ to provide optimal water quality and prevent the bitter taste that the consumer may detect [29]. Additionally, calcium or magnesium chloride concentrations may not be detected by the consumer until they reach levels of $1,000 \mathrm{mg} / \mathrm{L}$ or greater. While chlorides in and of itself pose little threat to human health, when paired with the cation sodium, both heart and kidney diseases may arise. 

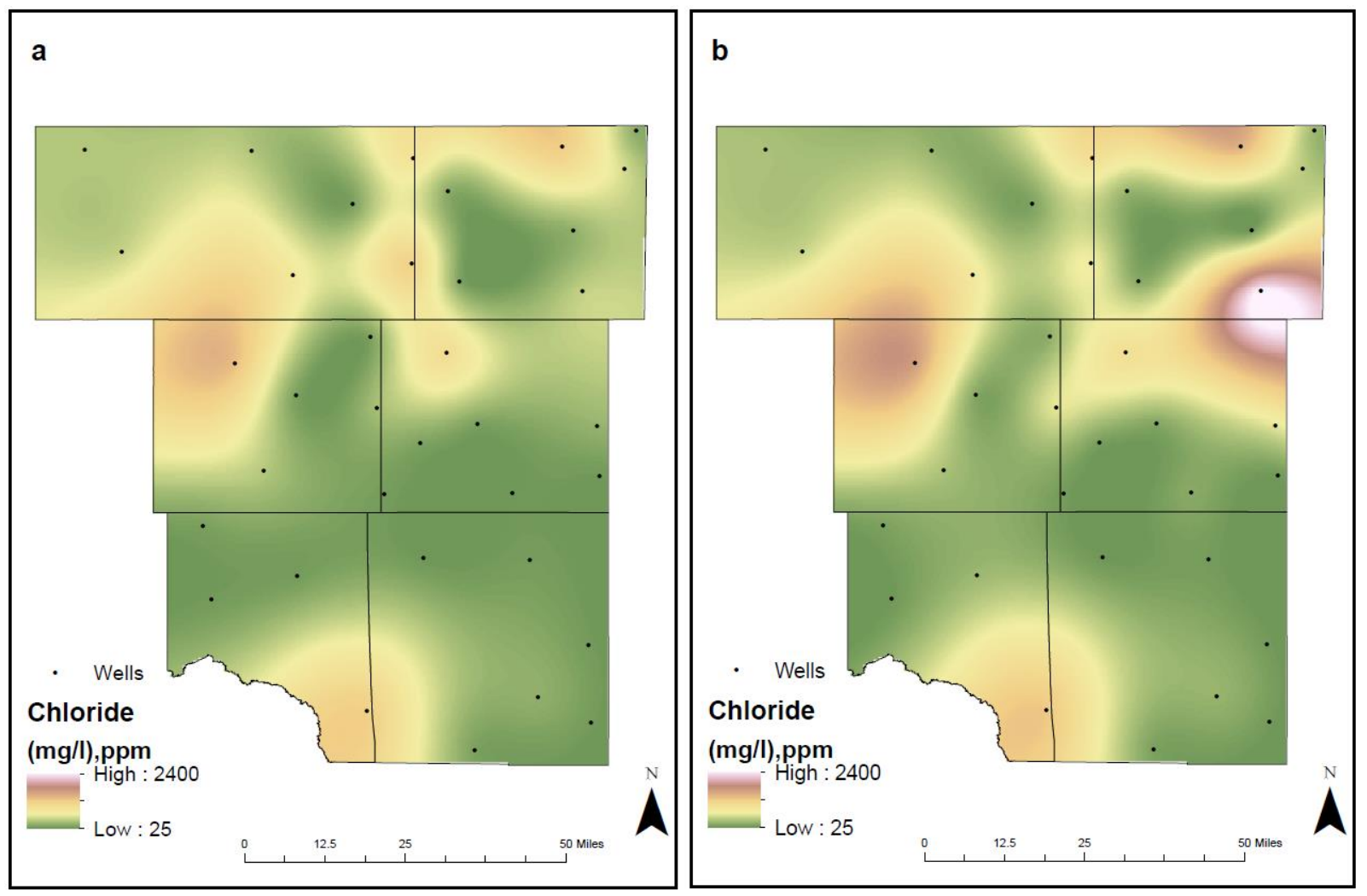

Fig 6. Spatial distribution of chloride in the study area for (a) 1992-2005 and (b) 2006-2019.

Between the two separate time intervals, chloride concentrations have remained relatively low except for three locations: Martin County, Southern Crane County and Northwestern Ector County. In Martin County, chloride levels have risen from 406 mg/L in 1992-2005 to 2,400 $\mathrm{mg} / \mathrm{L}$ in 2006-2019 (Fig 6). This dramatic increase in concentrations is attributed to the development of additional farmland and the pollution factors associated with the production of cultivated crops. Furthermore, the depth of the underlying Ogallala aquifer in this region is shallow, allowing for chlorides to penetrate through the subsurface easily. In both Southern Crane County and Northwestern Ector County, chloride concentrations have remained high between the two separate time intervals. Both locations have shallow depth of their underlying aquifer making them susceptible to contamination.

Fluids associated with the production of oil and gas commonly consist of sodium chloride (saline/brines) and contain increased concentrations of total dissolved solids [30]. These fluids also consist of heavy metals and Naturally Occurring Radioactive Material (NORM), specifically $\mathrm{Ra}^{226}$ from natural decay of $\mathrm{U}^{238}$ in shales, and must be disposed of properly to prevent 
degradation of the municipal water treatment facility. Contamination of groundwater with oilfield brines is predominantly associated with surface spills, where fluids can reach shallow groundwaters due to leaking tanks, flowline ruptures, or other oilfield mechanical failures [6, 30]. To determine whether the groundwater has been contaminated from a spill, chloride delineations must be obtained to identify the depth that the brines have penetrated through the subsurface.

\subsection{Fluoride}

Fluoride $(\mathrm{F})$ is essential for the maintenance and solidification of our bones and to prevent dental decay. It has beneficial effects on teeth and bones when it is present at low concentration in drinking water. Fluoride in water keeps teeth strong and reduces cavities by about $25 \%$ in children and adults. However, it may cause mottling of the teeth depending on the concentration, the age of the child, the amount of drinking water consumed, and the susceptibility of the individual [31]. The presence of fluorides in groundwater is most associated with weathering where water passing through the subsurface encounters fluorine bearing minerals [32]. Through environmental studies of fluoride in the subsurface, there is a direct correlation between mobility of $\mathrm{pH}$ and fluoride [24]. Soils that are more acidic allow for an increase of fluoride mobility and leaching where plant roots may subsequently accumulate the additional fluoride. This characteristic is demonstrated within the agricultural fields of southeast Martin County (Fig 7). In this region, there is a noticeable decrease in the concentration of fluoride between the two different time intervals. 

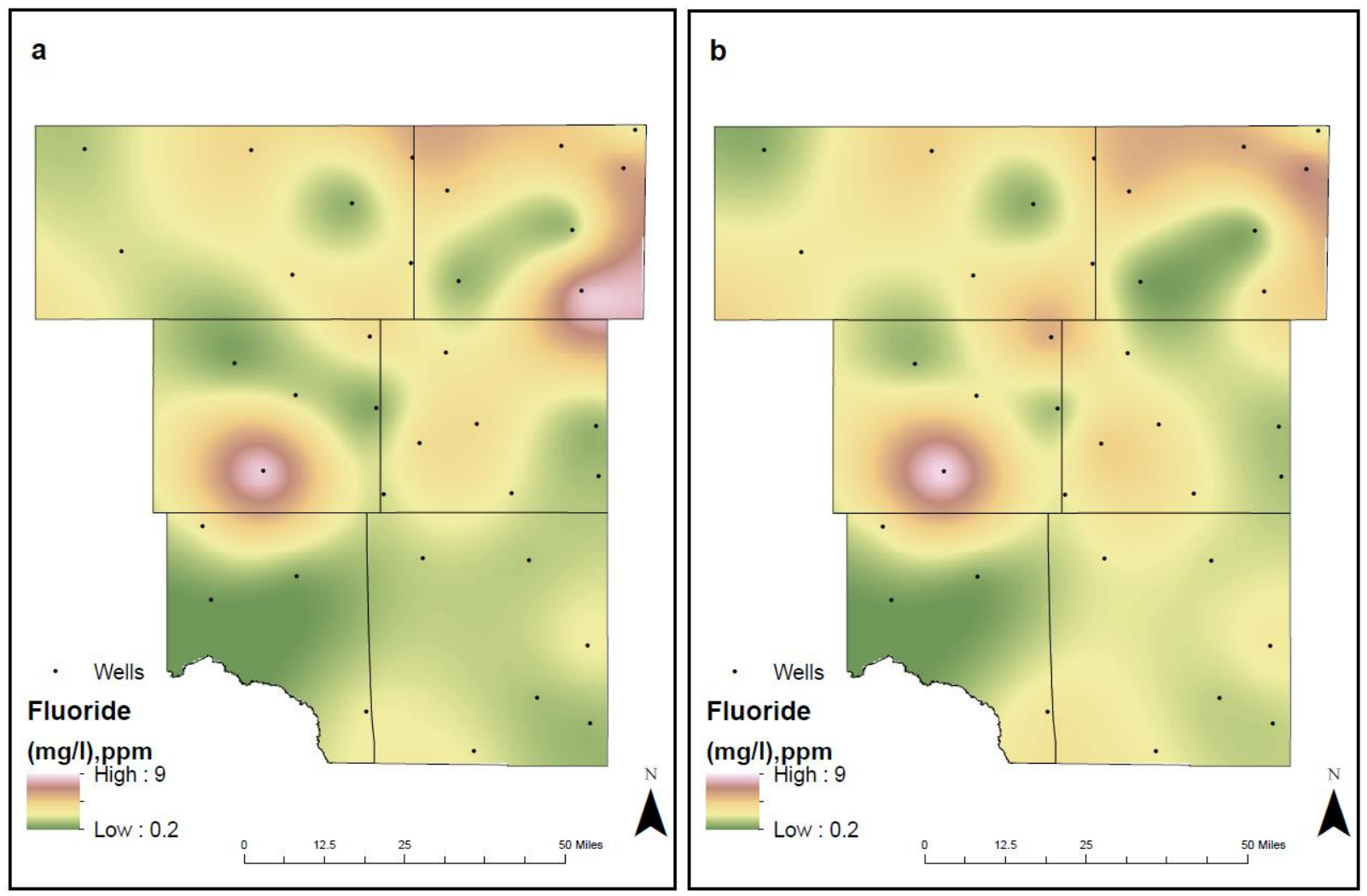

Fig 7. Spatial distribution of fluoride in the study are for (a) 1992-2005 and (b) 2006-2019.

Land-cover change from 1992 to 2011 indicates a substantial transformation of grass and bush to an area dominated by cultivated crops (Fig 10). As land turned to crops and the $\mathrm{pH}$ became acidic, plants began to uptake additional fluoride decreasing the concentration of the contaminant within groundwater. Fluoride concentration levels decreased from $7.8 \mathrm{mg} / \mathrm{L}$ in 1992-2005 to $3.35 \mathrm{mg} / \mathrm{L}$ in 2006-2019. Regions consisting of lower annual rate of precipitation generally have a higher concentration of fluoride than regions with a higher annual rate of precipitation [31]. The average annual precipitation within the study area ranges from 13-18 inches, potentially increasing the concentration of fluorides in groundwater. Additionally, "residence time", or the time it takes for groundwater to reach a well or stream, determines contaminant concentrations. In unconfined aquifers such as those of the Ogallala, EdwardsTrinity Plateau, and Pecos Valley, residence time can range from days to years. This swift migration of groundwater contributes to the overall decline in fluoride concentrations. Whereas confined aquifers such as the Dockum, groundwater residence time can range from centuries to millennia, preventing rapid removal of contaminants. 


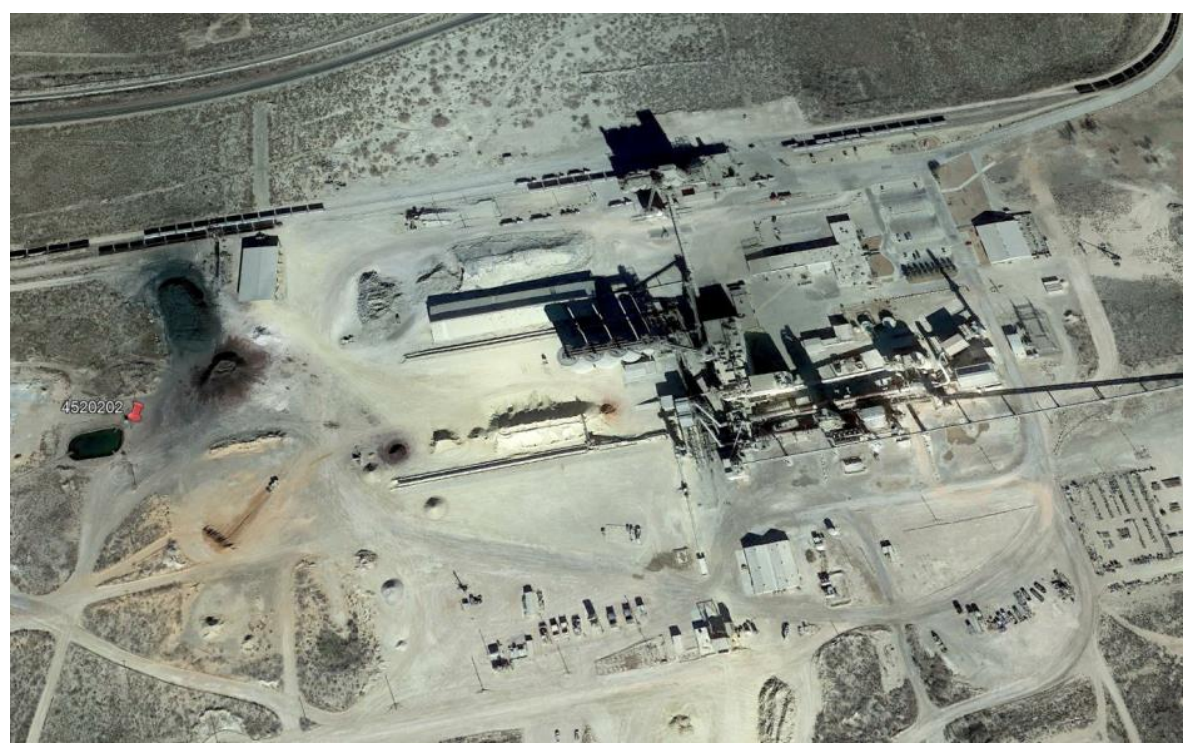

Fig 8. Location of well (ID: 4520202) adjacent to the cement production facility in southwest Ector County (image from Google Earth).

While fluoride concentrations have remained relatively consistent throughout the study area, one well (ID: 4520202) within southwest Ector County accounts for the highest accumulation of fluorides. Concentration limits have remained relatively consistent from 8.27 $\mathrm{mg} / \mathrm{L}$ in 1992-2005 and 8.55 mg/L in 2006-2019, well above the MCL of 4.0 MG/L. Located at the site of this well is a cement production facility (Fig 8). Fluorspar (calcium fluoride) is a common mineralizing agent in the manufacturing of cement [33]. In the oilfield, casing cement is used to isolate oil, gas, and water zones from the wellbore while also bonding the casing to the wall. Runoff and infiltration from the production of these materials, has resulted in the elevated readings observed. Furthermore, this well passes through the confined Dockum aquifer, where groundwater has an increased residence time and natural attenuation of the contaminant is lower.

\subsection{Nitrate}

Nitrate $\left(\mathrm{NO}_{3}{ }^{-}\right)$is a naturally occurring compound to sustain healthy plants in the ecosystem. It is in a more stable oxidation state than nitrite $\left(\mathrm{NO}_{2}{ }^{-}\right)$due to its extra oxygen, resulting in nitrite being detected with increased concentrations in a reducing environment [34]. While nitrates are found naturally occurring in groundwater, elevated concentrations are typically the result of 
anthropogenic activities $[35,36]$. Contamination of the groundwater from nitrates is frequently associated with infiltration of inorganic nitrogen fertilizers and livestock waste from agricultural procedures [36]. Nitrogen fertilizers are commonly applied annually to increase the overall quality of cultivated crops and increase output. These fertilizers can reach the groundwater through nitrate leaching in the subsurface.

The Environmental Protection Agency (EPA) has established a specific MCL for nitrate at $10 \mathrm{mg} / \mathrm{L}$ and elevated concentrations pose a small threat to human health, particularly in infants [35]. Groundwater wells rarely exceed this limit unless located in regions with increased agricultural activity. Well depth is an underlying factor affecting the concentration levels of nitrate in groundwater. As well depth increases, nitrate levels decrease, whereas shallower wells are observed to have the highest concentrations. This results from the leachate's ability to penetrate through the subsurface easier and reach the underlying aquifer. Groundwater wells drawing from the deepest Dockum aquifer had the lowest levels, whereas the shallower Ogallala contained elevated nitrate concentrations.
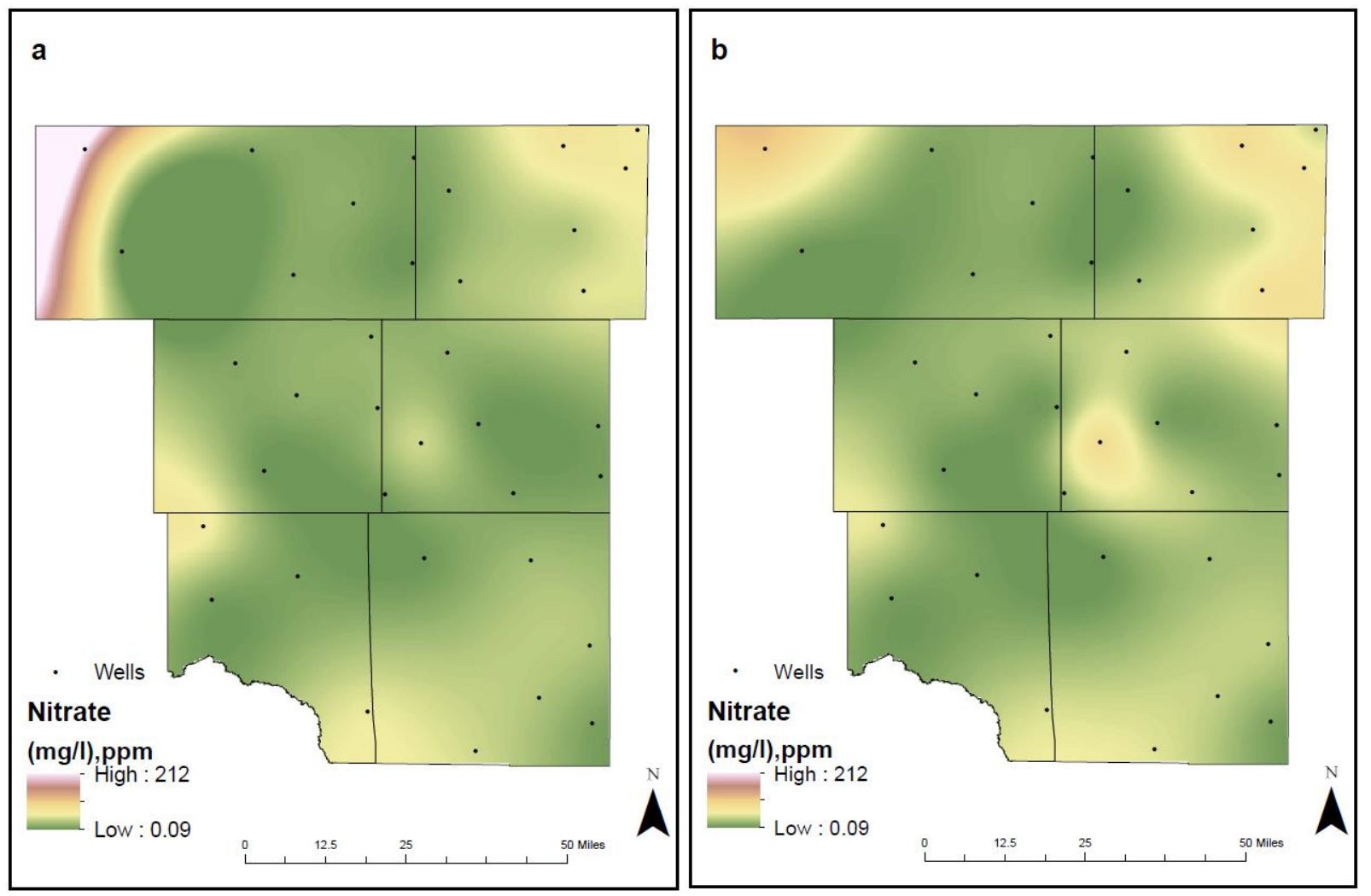

Fig 9. Spatial distribution of nitrate in the study area for (a) 1992-2005 and (b) 2006-2019. 
From 1992-2005 the highest nitrate levels were observed in Northwest Andrews County, east Martin County, and south of the city of Midland. Between the two separate time intervals, there was a noticeable shift in concentrations (Fig 9). The concentrated animal feeding operation in northwest Andrews County experienced a reduction in nitrate levels, potentially from a decrease in operations or through better management processes. The percentage of crop increased within the study area, most notably in Eastern Martin County (Fig 12). Coupled with a shallow groundwater well depth, this resulted in nitrate levels continually increasing over time in this region. Furthermore, as the city of Midland continuously experienced urban growth, the application of inorganic nitrate fertilizers on household lawns and public parks elevated nitrate concentrations [37].

\subsection{Arsenic}

Arsenic is naturally found within the subsurface as a trace element on rocks or soils and is commonly used in agriculture activities. The two valence states of arsenic often found in groundwater are arsenite $\left(\mathrm{As}^{+3}\right)$ and arsenate $\left(\mathrm{As}^{5+}\right)$, but concentrations rarely exceed the recommended EPA MCL of $10 \mu \mathrm{g} / \mathrm{L}[2,38]$. Arsenic poisoning (arsenicosis) can occur from exposure of $50 \mu \mathrm{g} / \mathrm{L}$ or greater contaminated groundwater and can lead to harmful effects on the human body such as an increased risk of cancer, diabetes, and damage to internal organs [6, 25]. Within alkaline environments ( $\mathrm{pH}$ greater than 7), arsenic becomes mobilized allowing for increased concentrations to be observed. These environments promote the release of arsenic through the electrostatic repulsion of the negatively charged Fe oxides/hydroxides and arsenic compounds. 

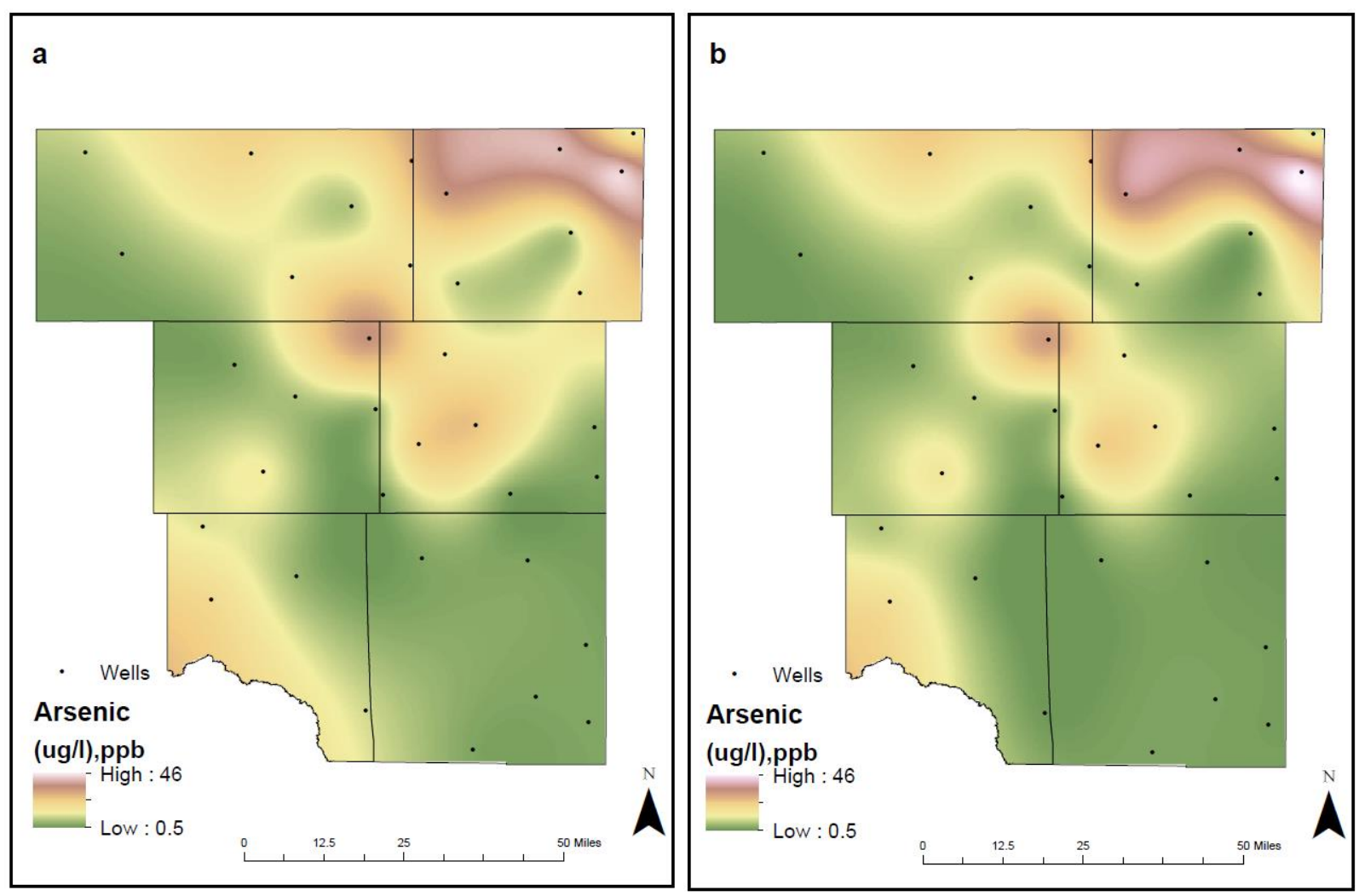

Fig 10. Spatial distribution of arsenic in the study are for (a) 1992-2005 and (b) 2006-2019.

The unconfined Ogallala aquifer contains the highest concentrations of arsenic where levels reach $45.5 \mu \mathrm{g} / \mathrm{L}$ (2006-2019) in northeast Martin County (Fig 10). Between the two separate time intervals, $\mathrm{pH}$ begins to shift to becoming more acidic within Northeast Midland County and Southeast Martin County. This shift resulted in a decrease in mobility of $\mathrm{pH}$ and disrupted further release of arsenic in groundwater. Water quality improved between the two different time intervals within the city of Midland from $23.87 \mu \mathrm{g} / \mathrm{L}$ in $1992-2005$ to $17.02 \mu \mathrm{g} / \mathrm{L}$ in 2006-2019. Furthermore, as pH or alkalinity increased in Northeast Martin County, the concentration levels remained consistent, resulting from mobility of arsenic in the subsurface.

Other potential inputs of arsenic in groundwater occur when petroleum hydrocarbon releases create reducing environments allowing for its mobilization [39]. Microbial activity increases the degradation of the hydrocarbons and consumes terminal electron acceptors producing these environments. Once the microbial activity has progressed and there is a reduction in the redox conditions, the concentration of the arsenic in groundwater will decrease and return to its ambient levels $[39,40]$. While exposure to high concentrations can be fatal, 
smaller concentrations (8-14 $\mu \mathrm{g} / \mathrm{L})$ can also lead to damaging effects such as skin lesions [38]. It's important for individuals obtaining drinking water from wells to regularly test and purify for arsenic to prevent these damaging effects.

\subsection{Total groundwater quality}

Water table can change over time due to changes in precipitation patterns, streamflow amount, and human-induced changes such as groundwater pumping and land development [11, 41]. Changes in water table in wells are driven by the interplay between groundwater recharge and discharge to and from aquifers. In general, water tables in wells decline due to increased groundwater withdrawal and/or reduced aquifer recharge. The risk of contamination is greater for unconfined (water-table) aquifers than for confined aquifers because they usually are nearer to the land surface, and they lack an overlying confining layer to impeding the movement of contaminants. Because groundwater moves slowly in the subsurface and many contaminants sorb to the sediments, restoration of a contaminated aquifer is difficult. In unconfined aquifers, contaminants from the soil or subsurface will directly affect the groundwater quality.

A wide range of different chemicals can be dissolved in groundwater as a result of interactions with the atmosphere, the surficial environment, soil and bedrock. The mutual influence of various chemical factors helps to evaluate hydrological processes responsible for changes in the groundwater quality. Groundwater tends to have much higher concentrations of most constituents than the surface waters do, and deep groundwater that has been in contact with the rock for a long time tends to have higher concentrations of the constituents than the shallow water. Shallow groundwater consists of $\mathrm{Ca}$ (calcium) $-\mathrm{Na}$ (sodium) $-\mathrm{HCO}_{3}$ (bicarbonate) dominantly formed by the interaction between atmospherically recharged meteoric water with the soil and shallow bedrock. These waters are usually fresh but upwelling of deeper saline fluids or saline intrusions from adjacent seawater bodies can influence their chemical composition [41]. Intermediate or deep depths groundwater rapidly increase in concentration of constituents primarily by the addition of $\mathrm{SO}_{4}$ (sulfate) and $\mathrm{Cl}$ (chloride). The concentration of bicarbonate ions decreases because of the precipitation of mineral phases such as calcite. Local variations in chemistry and anions may be due to a variety of rock-water interactions or local processes that result in $\mathrm{Na}-\mathrm{SO}_{4}, \mathrm{Na}-\mathrm{HCO}_{3}$, and $\mathrm{Mg}-\mathrm{SO}_{4}$ type waters. The $\mathrm{pH}$ begins to rise in this zone and oxygen-consuming reactions and redox mineral controls tend to lower the Eh [42]. 
Groundwater quality maps were created using a modified version first discussed by Ducci [19], where thematic maps were initially produced using the interpolation method and subsequently stacked developing the total groundwater quality map [7, 19, 24]. The modified version utilizes a summation process, combining and calculating the six contaminants together, and defining regions of poor, medium, and optimum groundwater conditions (Table 4). While not all contaminants have the same unit of measurement, the conversion of micrograms in arsenic to milligrams would result in a variable that is insignificant to the overall groundwater quality. Furthermore, the effects of $\mathrm{pH}$ are minimal on the total maps, as this variable has small fluctuations from $6.7-8.1$.

The maps of total groundwater qualities demonstrate the changes that have occurred in 1992-2005 and 2006-2019 (Fig 11), identifying areas where additional environmental studies or regulatory practices could be implemented to improve overall water quality. Between the two separate time intervals, there is a moderate decrease in the amount of optimum groundwater quality within the study area. The two regions of notably poor quality are in Eastern Martin County and Northwest Ector County. This decrease in overall groundwater quality is attributed to the elevated levels of TDS and chlorides associated through anthropogenic activities. Within the city of Midland, groundwater quality has remained consistent throughout the time intervals with medium contaminant concentrations being observed. Odessa has experienced a slight decrease in groundwater quality due to the result of population growth and urban development. Table 5 showed the average of all different parameters in the study area for (a) 1992-2005 and (b) 2006-2019.

Table 4. Groundwater conditions and the corresponding total concentrations.

\begin{tabular}{cc}
\hline Groundwater conditions & Total concentrations \\
\hline Optimum & $0-2,600$ \\
Medium & $2,600-5,200$ \\
Poor & $5,200-7,800$ \\
\hline
\end{tabular}




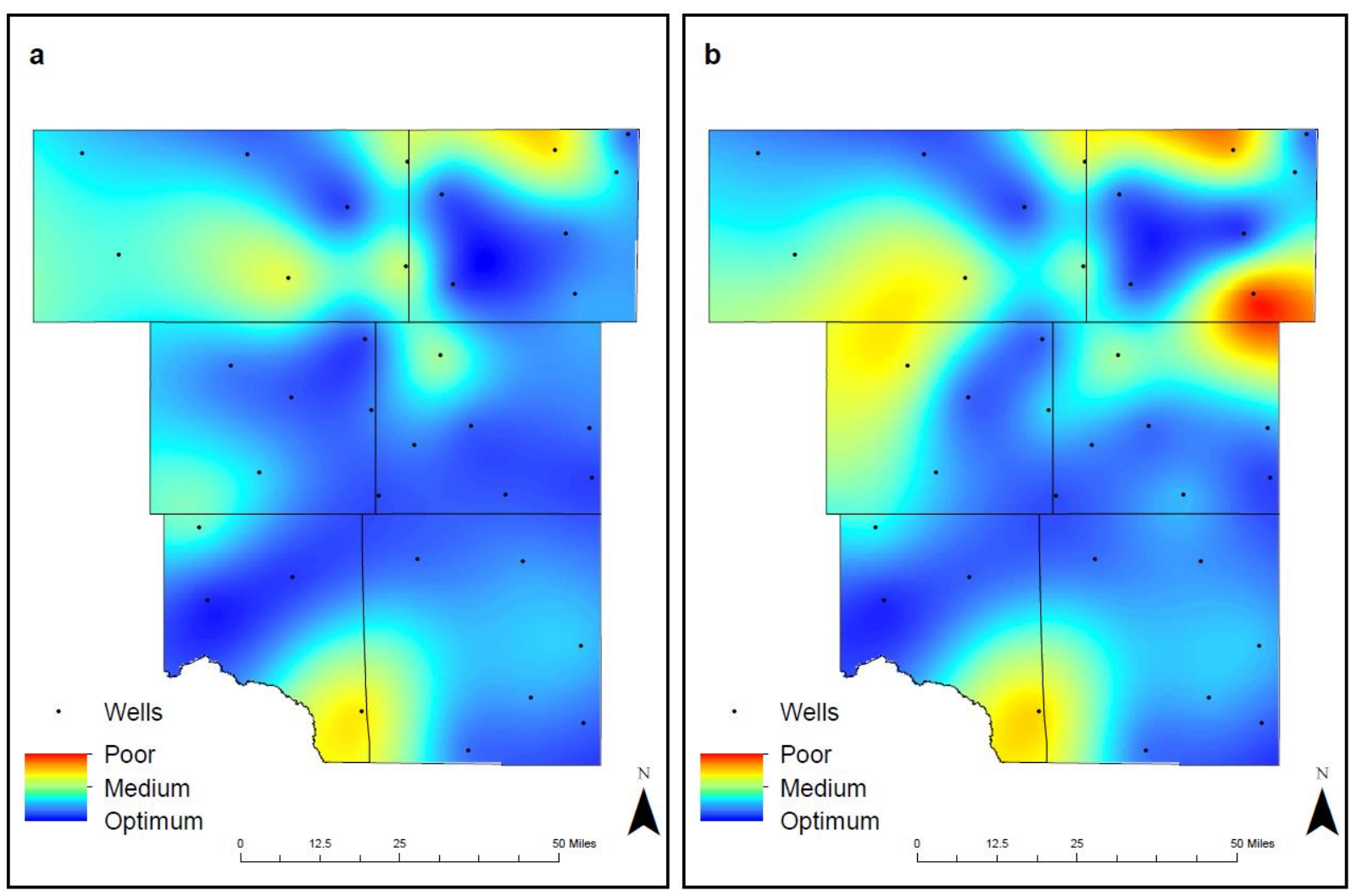

Fig 11. Spatial distribution of total groundwater quality from optimum to poor conditions in the study area for (a) 1992-2005 and (b) 2006-2019. 
Table 5. The averages of six groundwater parameters in the study area for (a) 1992-2005 and (b) 2006-2019

\begin{tabular}{|c|c|c|c|c|c|c|c|c|c|c|c|c|}
\hline \multirow[b]{2}{*}{ County } & \multicolumn{6}{|c|}{$1992-2005$} & \multicolumn{6}{|c|}{ 2006-2019 } \\
\hline & $\begin{array}{c}\mathrm{pH} \\
(\mathrm{SU})\end{array}$ & $\begin{array}{c}\text { TDS } \\
(\mathrm{mg} / \mathrm{L})\end{array}$ & $\begin{array}{l}\text { Chloride } \\
(\mathrm{mg} / \mathrm{L})\end{array}$ & $\begin{array}{c}\text { Fluoride } \\
(\mathrm{mg} / \mathrm{L})\end{array}$ & $\begin{array}{l}\text { Nitrate } \\
(\mathrm{mg} / \mathrm{L})\end{array}$ & $\begin{array}{c}\text { Arsenic } \\
(\mu \mathrm{g} / \mathrm{L})\end{array}$ & $\begin{array}{c}\mathrm{pH} \\
(\mathrm{SU})\end{array}$ & $\begin{array}{c}\text { TDS } \\
(\mathrm{mg} / \mathrm{L})\end{array}$ & $\begin{array}{c}\text { Chloride } \\
(\mathrm{mg} / \mathrm{L})\end{array}$ & $\begin{array}{c}\text { Fluoride } \\
(\mathrm{mg} / \mathrm{L})\end{array}$ & $\begin{array}{l}\text { Nitrate } \\
(\mathrm{mg} / \mathrm{L})\end{array}$ & $\begin{array}{c}\text { Arsenic } \\
(\mu \mathrm{g} / \mathrm{L})\end{array}$ \\
\hline Andrew & 7.3 & 2347.5 & 551.8 & 2.7 & 36.2 & 12.3 & 7.3 & 2283.2 & 478.3 & 2.7 & 21.0 & 10.5 \\
\hline Martin & 7.2 & 1540.9 & 400.3 & 3.9 & 42.7 & 21.8 & 7.1 & 2096.3 & 701.4 & 3.5 & 46.4 & 20.9 \\
\hline Ector & 7.2 & 849.0 & 433.9 & 3.0 & 12.5 & 11.1 & 7.2 & 1693.2 & 563.3 & 5.5 & 13.2 & 12.3 \\
\hline Midland & 7.2 & 1110.7 & 213.6 & 2.3 & 11.5 & 9.6 & 7.0 & 1292.3 & 278.0 & 2.5 & 30.3 & 8.6 \\
\hline Crane & 7.3 & 2003.3 & 337.9 & 1.5 & 30.2 & 9.7 & 7.3 & 2005.2 & 401.7 & 1.7 & 24.5 & 7.2 \\
\hline Upton & 7.1 & 1347.8 & 82.6 & 1.7 & 20.7 & 2.0 & 7.1 & 1356.6 & 87.9 & 2.1 & 24.1 & 1.7 \\
\hline Total & 7.2 & 1533.2 & 336.7 & 2.5 & 25.6 & 11.1 & 7.2 & 1787.8 & 418.4 & 3.0 & 26.6 & 10.2 \\
\hline
\end{tabular}




\subsection{Environmental change}

With the advancement of horizontal drilling and hydraulic fracturing, previously untouched shale strata were now viable, greatly increasing the amount of recoverable reserves. As a result, rig count dramatically rose to nearly 500 at the end of 2011 and oil prices peaked at over $\$ 100$ per barrel, ultimately allowing production to reach 1 million barrels per day [43]. Additionally, associated oilfield facilities grew to account for the increase in production. These factors resulted in a considerable change in both economic growth and land cover from 1992 to 2011 where the amount of developed land increased by $11.78 \mathrm{~km}^{2}$ or $176 \%$ while also decreasing the percentage of barren and grass throughout the study area (Table 6).
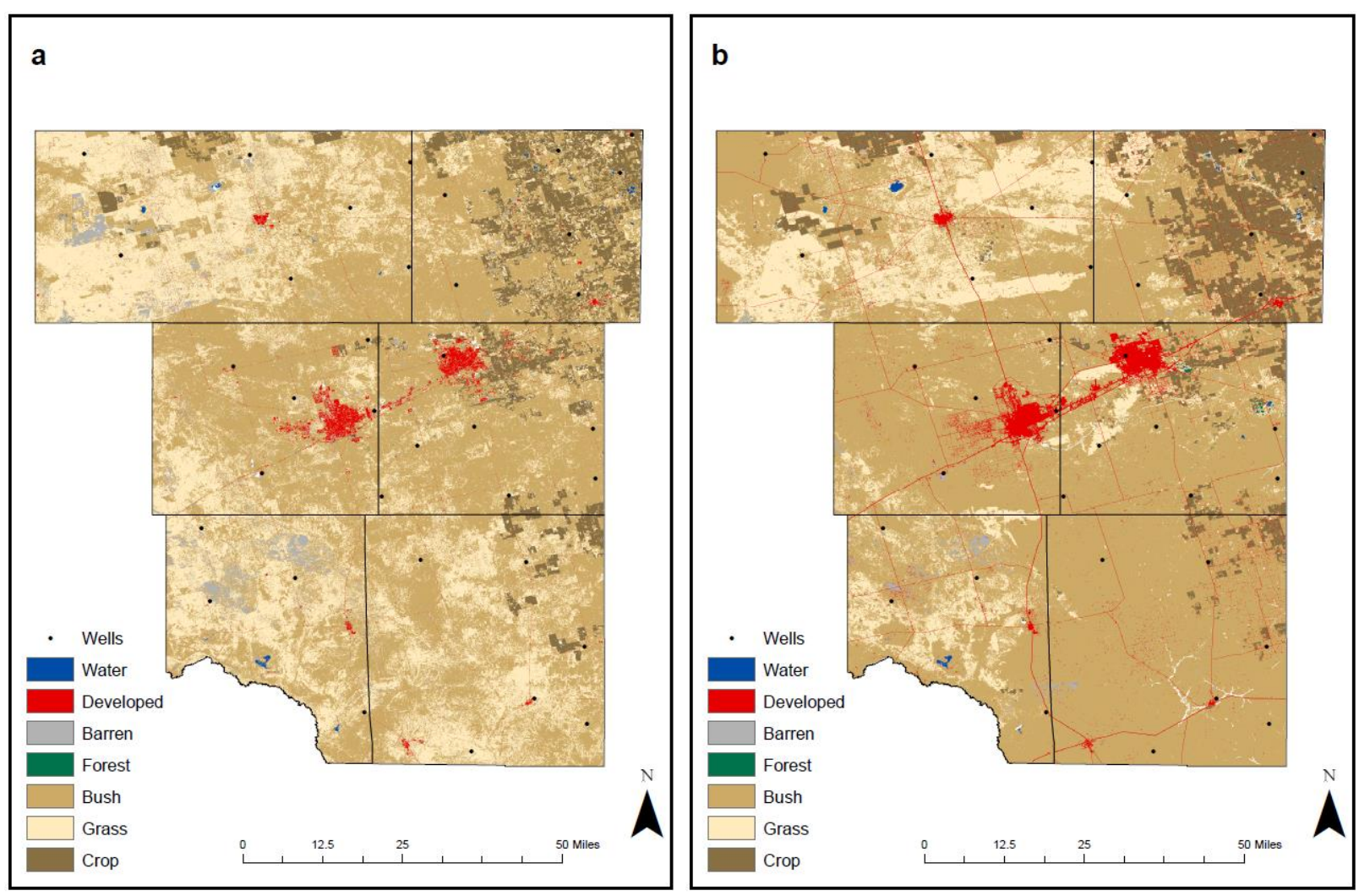

Fig 12. Land-cover maps of the study area; (a) NLCD 1992 and (b) NLCD 2011. NLCD: National Land Cover Dataset

Furthermore, the shale boom resulted in a noticeable increase of well sites and production pads scattered throughout West Texas, contributing to the growth of Developed land (Fig 12). The population within Midland rose from 89,443 in 1990 to 111,147 in 2010, while Odessa 
expanded from 89,699 in 1990 to 99,940 in 2010 [44]. Economic benefits associated with horizontal drilling and hydraulic fracturing such as higher incomes and extra jobs resulted in this flux of population growth. The increase within these two cities from 1992 to 2011 is depicted with a denser packing of the developed land.

Table 6. The area for each land-cover type in the study area (unit: $\mathrm{km}^{2}$ ).

\begin{tabular}{lrrr}
\hline & NLCD 1992 & NLCD 2011 & Changes \\
\hline Water & $0.5(0.1 \%)$ & $0.6(0.1 \%)$ & $0.1(28.9 \%)$ \\
Developed & $6.7(1.2 \%)$ & $18.5(3.4 \%)$ & $11.8(176.1 \%)$ \\
Barren & $13.1(2.4 \%)$ & $4.0(0.7 \%)$ & $-9.1(-69.5 \%)$ \\
Forest & $0.1(0.0 \%)$ & $0.3(0.1 \%)$ & $0.2(277 \%)$ \\
Bush & $295.4(54.8 \%)$ & $378.5(70.2 \%)$ & $83.2(28.2 \%)$ \\
Grass & $184.8(34.3 \%)$ & $91.6(17.0 \%)$ & $-93.2(-50.4 \%)$ \\
Crop & $38.5(7.1 \%)$ & $43.9(8.1 \%)$ & $5.4(14.1 \%)$ \\
Others & - & $1.6(0.3 \%)$ & - \\
\hline Total & $539.0(100 \%)$ & $538.9(100 \%)$ & - \\
\hline
\end{tabular}

Technological advances throughout the 1990's and 2000's allowed for an increase in agricultural output and quality. Global Positioning Systems (GPS) continually improved throughout the 1990's and into the 2000's, resulting in automated farm equipment that efficiently map and plan fields, increase production, and reduce the overall price from seed to harvest. Within this arid region, the primary water source is the Ogallala aquifer, which provides the necessary groundwater vital to produce various crops. The development of center pivot irrigation in the 1950's supported farmers to establish crops in these arid regions. Furthermore, genetic engineering of crops in the mid to late 1990's, lead to plants that are more resistant to insects, weeds, and viruses [45]. These factors, coupled with a growing demand from a rising population, allowed the percentage of Crop from 1992 to 2011 to increase by 14\%, primarily within Martin County. To protect groundwater quality from further human activities, government agencies and local communities should adopt the following strategies: regulating the disposal of produced fluids from oil and gas activities, controlling the amount and type of agricultural chemicals, 
promoting responsible use of waste drainages in the vicinity of mining areas, and boosting the development of rural and industrial infrastructures.

\section{Conclusions}

We evaluated groundwater quality parameters such as $\mathrm{pH}$, TDS, chloride, fluoride, nitrate, and arsenic from 1992-2005 and 2006-2019 and identified land cover maps where specific changes in the environment effected groundwater quality in the Permian Basin, Texas. Utilizing advanced geospatial techniques, these parameters described areas from optimum and poor groundwater conditions. Factors that contribute to the level of contaminants in groundwater are natural sources, anthropogenic activities, and aquifer depth. The mobilization of arsenic and fluoride from natural sources resulted primarily in the fluctuations of the subsurface $\mathrm{pH}$. These alterations in $\mathrm{pH}$ directly resulted in varying concentrations of contaminates within the groundwater. Anthropogenic activities such as petroleum spills and inorganic chemical fertilizers contributed to the contaminant load in groundwater. An underlying factor for the contamination is aquifer depth, where contaminants may reach shallower unconfined aquifers quickly, yet have a decrease in residence time. Land cover in developed and crop significantly rose from 1992 to 2011 due to the increase in production from unconventional natural resources and advances in crop management. These increases consequently resulted in a decrease of overall groundwater quality in the Permian Basin, Texas. Total groundwater quality maps demonstrate a transition of water quality related to the advancement of urban development and population. This research provides significant information for the management of groundwater resources and the response to these potential changes in the Permian Basin, Texas.

\section{Author Contributions}

R.N. collected detailed information, calculated the groundwater quality, developed the methodology, and analyzed the results with arguments. J.H. designed the overall structure, made critical revisions and contributed for the paper. All authors reviewed and approved of the final manuscript. 


\section{Acknowledgements}

This work was supported financially by the University of Texas System Rising STARs Program - Funding.

\section{References}

1. EPA (Environmental Protection Agency). Drinking water standard and advisory tables. Washington, DC: EPA. 2018; Available from https://www.epa.gov/dwstandardsregulations/2018-drinking-water-standards-andadvisory-tables.

2. EPA (Environmental Protection Agency). Parameters of water quality - Interpretation and standards wellhead protection. Washington, DC: EPA. 2001; Available from https://www.epa.ie/pubs/advice/water/quality/Water_Quality.pdf

3. WHO (World Health Organization). Guidelines for drinking water quality, fourth edition incorporating the first addendum. Geneva: WHO. 2017; Available from https://www.who.int/water_sanitation_health/publications/drinking-water-qualityguidelines-4-including-1st-addendum/en/

4. EPA (Environmental Protection Agency). Guidance on the authorisation of discharges to groundwater. Washington, DC: EPA. 2011; Available from https://www.epa.ie/pubs/reports/water/ground/dischgw/.

5. Fritch TG, McKnight CL, Yeldman JC, Dworkin SI, Arnold JG. A predictive modeling approach to assessing the groundwater pollution susceptibility of the Paluxy Aquifer, Central Texas, using a geographic information system. Environmental Geology. 2000. 39(9): 1063-1069. doi: https://doi.org/10.1007/s002549900078

6. Rodriguez J, Heo J, Park J, Lee S, Miranda K. Inorganic pollutants in the water of Midland and Odessa, Permian Basin, west Texas. Air, Soil and Water Research. 2019; 12:1-7. doi: https://doi.org/10.1177/1178622119861089

7. Nas B, Berktay A. Groundwater quality mapping in urban groundwater using GIS. Environmental Monitoring and Assessment. 2008; 160: 215-227. doi: https://doi.org/10.1007/s10661-008-0689-4

8. Wolaver BD, Pierre JP, Labay BJ, LaDuc TJ, Duran CM, Ryberg WA, Hibbitts TJ. An approach for evaluating changes in land-use from energy sprawl and other anthropogenic 
activities with implications for biotic resource management. Environmental Earth Sciences. 2018; 77: 1-12. doi: https://doi.org/10.1007/s12665-018-7323-8

9. Long S (2014). Direct and indirect challenges for water quality from the hydraulic fracturing industry. Journal - American Water Works Association. 106: 53-57.

10. Mehany M, Kumar S (2019). Analyzing the feasibility of fracking in the U.S. using macro level life cycle cost analysis and assessment approaches - A foundational study. Sustainable Production and Consumption. 20: 375-388.

11. Rodriguez J, Heo J, Kim K. The impact of hydraulic fracturing on groundwater quality in the Permian Basin, west Texas, USA. Water. 2020; 12: 796. doi: https://doi.org/10.3390/w12030796

12. EPA (Environmental Protection Agency) (2016). Hydraulic Fracturing for Oil and Gas: Impacts from the Hydraulic Fracturing Water Cycle on Drinking Water Resources in the United States. Available from https://cfpub.epa.gov/ncea/hfstudy/recordisplay.cfm?deid=332990

13. Ashworth JB, Hopkins J. Aquifers of Texas. TWDB (Texas Water Development Board). 1995; Report 345. Available from https://www.twdb.texas.gov/publications/reports/numbered_reports/doc/R345/R345Com plete.pdf

14. Anaya R, Jones I. Groundwater availability model for the Edwards-Trinity (Plateau) and Pecos Valley aquifers of Texas. TWDB (Texas Water Development Board). 2009; Report 373. Available from

https://www.twdb.texas.gov/groundwater/models/alt/eddt_p_2011/ETP_PV_One_Layer_ Model.pdf

15. George PG, Mace RE, Petrossian R. Aquifers of Texas. TWDB (Texas Water Development Board). 2011; Report 380. Available from https://www.twdb.texas.gov/publications/reports/numbered_reports/doc/R380_Aquiferso fTexas.pdf

16. Ashworth JB, Christian P, Waterreus TC. Evaluation of groundwater-water resources in the southern High Plains of Texas. TWDB (Texas Water Development Board). (1991); Report 330. Available from 
http://www.twdb.texas.gov/publications/reports/numbered_reports/doc/R330/r330_south ernhighplains1991.pdf

17. Hopkins J. Water-quality evaluation of the Ogallala aquifer, Texas. TWDB (Texas Water Development Board). 1993; Report 342. Available from http://www.twdb.texas.gov/publications/reports/numbered_reports/doc/R342/R342.pdf

18. Schmandt J, Clarkson J, North GR. The Impact of global warming on Texas: Second edition. The University of Texas Press, 2011; 27-57.

19. Ducci D. GIS techniques for mapping groundwater contamination risk. Natural Hazards. 1999; 20: 279-294. Doi: https://doi.org/10.1023/A:1008192919933

20. Heo J. The impact of climate change on hydrology with geomorphology in northeast Texas. Journal of Earth Science and Engineering. 2018; 8: 1-7. doi: 10.17265/2159$\underline{581 X / 2018.01 .001}$

21. Heo J, DeCicco J. Spatial and temporal analysis of carbon sequestrations in the conterminous United States. Journal of Energy and Power Engineering. 2018; 12: 169176. doi: $10.17265 / 1934-8975 / 2018.04 .001$

22. USGS (U.S. Geological Survey). NLCD 2011 land cover. MRLC (Multi-Resolution Land Characteristics Consortium). Available from https://www.mrlc.gov/data/nlcd-2011-landcover-conus-0

23. Heo J, Yu J, Giardino JR, Cho H. Water resources response to climate and land-cover changes in a semi-arid watershed, New Mexico, USA. Terrestrial, Atmosphere and Oceanic Sciences. 2015; 26 (4): 463-474.

24. Chaudhary K, Saraswat PK, Khan S. Improvement in fluoride remediation technology using GIS based mapping of fluoride contaminated groundwater and microbe assisted phytoremediation. Ecotoxicology and Environmental Safety. 2018; 168 (30): 164-176. doi: $\underline{10.1016 / \text { j.ecoenv.2018.10.007 }}$

25. Hamidian AH, Razeghi N, Zhang Y, Yang M. Spatial distribution of arsenic in groundwater of Iran, a review. Journal of Geochemical Exploration. 2019; 201: 88-98. doi: $10.1016 /$ j.gexplo.2019.03.014

26. WHO (World Health Organization). Developing drinking-water quality regulations and standards. Geneva: WHO. 2018; Available from 


\section{https://www.who.int/water_sanitation_health/publications/developing-dwq-} regulations/en/

27. Hong S, Gan P, Chen A. Environmental control on soil $\mathrm{pH}$ in planted forest and its response to nitrogen deposition. Environmental Research. 2019; 172: 159-165. Doi: 10.1016/j.envres.2019.02.020

28. Devesa R, Dietrich AM. Guidance for optimizing drinking water taste by adjusting mineralization as measured by total dissolved solids (TDS). Desalination. 2018; 439: 147-154. doi: 10.1016/j.desal.2018.04.017

29. Kumar M, Puri A. A review of permissible limits of drinking water. Indian Journal of Occupational \& Environmental Medicine. 2012; 16(1): 40-44. doi: 10.4103/0019$\underline{5278.99696}$

30. Jackson RE, Gorody AW, Mayer B, Roy JW, Ryan MC, Van Stempvoort DR. Groundwater protection and unconventional gas extraction: the critical need for fieldbased hydrogeological research. Groundwater. 2013; 51(4): 488-510. doi:

\subsection{1/gwat.12074}

31. Fawell J, Bailey K, Chilton J, Dahi E, Fewtrell L, Magara Y. Fluoride in drinking water. World Health Organization (WHO) by IWA publishing, 2006; London.

32. Stephen P, Niyi A. Water fluoridation: a critical review of the physiological effects of ingested fluoride as a public health intervention. Scientific World Journal. 2014; 1-10. doi: $\underline{10.1155 / 2014 / 293019}$

33. Qunitero N. Examining the use of fluorspar in the cement industry. CEMEX Research Group. 2013; Available from https://www.cemex.com

34. Juntakut P, Snow DD, Haacker EMK, Ray C. The long term effect of agricultural, vadose zone and climatic factors on nitrate contamination in Nebraska's groundwater system. Journal of Contaminant Hydrology. 2019; 220: 33-48. doi: https://doi.org/10.1016/j.jconhyd.2018.11.007

35. Zhang WL, Tian ZX, Zhang N, Li XQ. Nitrate pollution of groundwater in northern China. Agriculture, Ecosystems and Environment. 1996; 59 (3): 223-231. doi: https://doi.org/10.1016/0167-8809(96)01052-3 
36. Wang Y, Ying H, Yin Y, Zheng H, Cui Z. Estimating soil nitrate leaching of nitrogen fertilizer from global meta-analysis. Science of the Total Environment. 2019; 657: 96102. doi: https://doi.org/10.1016/j.scitotenv.2018.12.029

37. Carrico AR, Raja US, Fraser J, Vandenbergh MP. Household and block level influences on residential fertilizer use. Landscape and Urban Planning. 2018; 178: 60-68. doi: https://doi.org/10.1016/j.landurbplan.2018.05.008

38. Ng JC, Wang J, Shraim A. A global health problem caused by arsenic from natural sources. Chemosphere; 2003; 52(9): 1353-1359. Doi: https://doi.org/10.1016/S0045$\underline{6535(03) 00470-3}$

39. Brown RA, Patterson KE, Zimmerman MD, Ririe GT. Attenuation of naturally occurring arsenic at petroleum hydrocarbon-impacted sites. American Petroleum Institute (API). 2010; Groundwater Arsenic Manual 1-41. Available from https://www.api.org/oil-andnatural-gas/environment/clean-water/ground-water/managing-arsenic-ingw

40. Medjor WO, Akpoveta VO, Adebowale ME. Remediation of hydrocarbons contaminated groundwater by silica encapsulation technique. Water-Energy Nexus. 2018; 1(2): 134141. doi: https://doi.org/10.1016/j.wen.2018.12.001

41. Zheng Y, Geen A, Stute M, Dhar R, Mo Z, Cheng Z, Horneman A, Gavrieli I, Simpson H, Versteeg R, Steckler M, Grazioli-Venier A, Goodbred S, Shahnewaz M, Shamsudduha M, Hoque M, Ahmed K. Geochemical and hydrogeological contrasts between shallow and deeper aquifers in two villages of Araihazar, Bangladesh:

Implications for deeper aquifers as drinking water sources, Geochimica et Cosmochimica Acta. 2005; 69: 5203-5218. doi: https://doi.org/10.1016/j.gca.2005.06.001

42. Zekâi S. Practical and Applied Hydrogeology, Elsevier. 2015; 424.

43. EIA (Energy Information Administration). Annual energy review 2011. EIA. 2012; Available from https://www.eia.gov/totalenergy/data/annual/pdf/aer.pdf

44. Cohen DT, Hatchard GW, Wilson SG. Population trends in incorporated places 2000 to 2013. U.S. Census Bureau. 2015; Available from https://www.census.gov/library/publications/2015/demo/p25-1142.html

45. Gaur RK, Verma RK, Khurana SMP. Genetic Engineering of Horticultural Crops. Elsevier. 2018; 23-46. 